\title{
A full-scale thermo-hydraulic simulator for the characterization of building heat cost allocation methods
}

\author{
Fabio Saba ${ }^{1,2,}{ }^{*}$, Marco Carlo Masoero ${ }^{2}$, and Vito Fernicola ${ }^{1}$ \\ ${ }^{1}$ INRIM, Istituto nazionale di ricerca metrologica, Strada delle Cacce 91, 10135 Torino, Italy \\ ${ }^{2}$ Dipartimento Energia, Politecnico di Torino, Corso Duca degli Abruzzi 24, 10129 Torino, Italy
}

\begin{abstract}
An innovative heat accounting method for apartment buildings, named EcoThermo, based on the estimation of water flow rates at each radiator by thermo-hydraulic modelling of the hot water distribution system, has been developed in the framework of the EU Programme FP7SME-2012. In order to validate this approach and to compare it with conventional Heat Cost Allocators (HCA), a full-scale thermo-hydraulic simulator has been recently built at INRIM. This INRIM test facility represents a real-scale hot water heating system consisting of a gas-fired boiler and 40 radiators of different characteristics, mimicking a four-story residential building. Each radiator is equipped with an electromagnetic flow meter and a pair of short-stem Pt100 PRTs immersed in the water flow for inlet and outlet water temperature measurement, such that the radiator thermal output can be determined by direct metering, providing an accurate reference value against which indirect allocation methods can be compared and assessed. The paper describes in detail the INRIM thermohydraulic simulator, highlighting its design features and metrological capabilities and discussing key results of the investigations carried out so far on different heat accounting approaches. The accuracy of the EcoThermo model has also been assessed against direct heat metering and HCA approach.
\end{abstract}

\section{Introduction}

Buildings account for about $40 \%$ of primary energy consumption and $36 \%$ of $\mathrm{CO}_{2}$ emissions in the EU [1]. The European Directive on Energy Efficiency 2012/27/EU [2] targets energy savings in buildings with a number of actions, among which the provision of individual heat meters or heat allocators for measuring individual heating consumption in apartment buildings supplied by district heating or conventional central heating systems. Direct heat metering is certainly the preferred and most accurate accounting method, also providing SI-traceability to such measurements. This solution, which is customarily applied to new buildings with zonal (horizontal) water distribution, cannot be installed in most older buildings adopting the vertical water distribution layout, which implies several heat

\footnotetext{
*Corresponding author: f.saba@inrim.it, fabio.saba@polito.it
} 
delivery points. In such cases, indirect heat accounting systems using heat cost allocators or insertion time counters are therefore used.

The direct measurement of the thermal energy exchanged by a fluid flow, by measuring its flow rate and temperature difference along a generic heat transfer circuit, is carried out by the Direct Heat Meters (DHM). These sensors are particularly important for district heating applications, since they are used for the measurement of the overall amount of thermal energy delivered to the users at the heat exchanger of the building substation. Moreover, in buildings with central heating systems characterized by typical multi-zone hot water distribution circuits, DHMs are used for measuring the individual heat consumption of each apartment, providing a correct allocation of heating costs. In particular, since the thermal energy bill can be split in a variable part, related to the actual heat consumption of the user, and a fixed part, related to the heat losses through the circuit and at the heater, DHMs installed at the apartment-zones of the hot water distribution network, in addition to the measurement of the overall thermal energy consumption of the building, allow providing a correct and fair evaluation of both the parts of the thermal energy bill. On the technical point of view, DHMs are regulated by the OIML R 75 [4] and the European Standard EN 1434 [5]. Moreover, in order to ensure customer protection through fair measurements and to eliminate trade barriers among member states, the 2004/22/CE Measuring Instrument Directive (MID) [6], which harmonizes the measuring instrument legislation in Europe, regulates and fixes the rules for the approval and initial verification of DHMs (Annex MI-004).

Wherever possible, DHMs should be used for heat accounting in multi-apartments and multi-purpose buildings with central heating/cooling systems supplied by either conventional sources or district heating/cooling networks. Anyway, in buildings with vertical hot water distribution networks (vertical risers central heating plant configuration), the use of DHMs for the correct allocation of heat consumption among the users can be practically and economically unfeasible because of installation constraints and high costs. In such cases, the Energy Efficiency Directive [2], recently implemented in Italy by the Decree 102/2014 [3], allows using indirect heat accounting systems, which carry out an estimation of thermal energy consumptions, based on the measurement of some parameters closely related, in particular, to the heat transfer from water radiators.

Indirect heat accounting systems provide an estimation of individual thermal energy consumptions in terms of number of "allocation units", allowing the sharing of the heating costs among the tenants, as a fraction of the whole thermal energy consumption of the building (usually measured by gas meters or DHMs). The two main typologies of indirect heat accounting systems available on the market are the heat cost allocators (HCA) and the insertion time counters (ITC). Both these devices are based on the indirect estimation of the heat output of water radiators, which are characterized according to the European Standard EN $442[7,8]$. Such devices for indirect heat accounting, unlike DHMs, are not regulated by the MID, but are mandatory in order to improve energy efficiency and promote energy saving for those buildings in which the use of DHMs for heat cost allocation is unfeasible or not affordable. Of course, in order to ensure consumer protection, indirect heat accounting devices must be compliant to proper regulations and technical standards, like the EN 834 [9] for heat cost allocators and the UNI TR 11388 [10] for insertion time counters.

Since the "allocation units" provided by indirect heat accounting devices must be considered as rough estimations of the actual amount of thermal energy consumed by each user, they can be used, exclusively, to assess the sharing of the variable part of the thermal energy bill among the tenants of apartment buildings. According to the criteria for heat cost allocation in multi-apartment or multi-purpose buildings, in which is not possible to use DHMs for the evaluation of individual heat consumptions [11], the splitting up of the total 
heating cost in a fixed part, related to the heat losses through the circuit and the heater, and a variable part, related to the actual individual heat consumptions, should be based on the preliminary definition of proper constant fractions, which can be chosen taking into account the energy performance certificate of the building and the typical occupancy behaviour. Once such fixed and variable fractions have been defined, the fixed part of the overall thermal energy bill of the building is usually divided among the users according to the size of their apartments, while the variable part is divided among the tenants according to the corresponding number of "allocation units" provided by the indirect heat accounting devices.

The accuracy of HCAs or ITCs may be negatively affected by the inadequate knowledge of the thermal emission characteristics of water radiators and by installation effects in actual applications [12-14]. There is therefore room for improvement in the accuracy of heat cost allocation in older centralized systems by adopting innovative approaches [15]. Along this line, the EcoThermo heat accounting method has been developed and tested in the context of the EU $7^{\text {th }}$ Framework Program for Small and Medium-sized Enterprises FP7-SME-2012 "Innovative green technology for smart energy saving on existing residential buildings with centralized heating/cooling generators" [16, 17]. It is based on the network modelling of the thermal-hydraulic circuit of a generic central heating system, where the hydraulic characteristics (head loss coefficients) of each branch of the water distribution network are preliminarily estimated by means of a suitable parameter identification procedure. Once the hydraulic characteristics of the circuit have been identified, the water volumetric flow rates circulating through each open radiator can be estimated from the measurements of the overall volumetric flow rate and head loss, by solving the hydraulic model of the hot water distribution network. Thus, in addition to the inlet and outlet water temperature measurements at each heating body, it is possible to directly evaluate the thermal energy exchanged by the heat conveying fluid at each water radiator, providing an estimation of the radiator thermal output, which is independent from installation effects that may occur at actual operating conditions, since it does not rely on the knowledge of the thermal emission characteristics of water radiators.

In order to validate this approach and to compare it with conventional HCAs, a fullscale central heating system simulator has been realized at INRIM, in the context of the EU $7^{\text {th }}$ Framework Programme FP7-SME-2012, for testing heat cost allocation systems in the actual operating conditions of multi-apartment buildings [18]. The test facility consists of an automatically reconfigurable thermal-hydraulic circuit equipped with a sufficient number of sensors aimed at measuring all the physical quantities involved in direct heat metering. Namely, SI-traceable reference direct heat meter assemblies are installed on each of the 40 water radiators of the hot water distribution network, in order to provide the reference measurement of the thermal energy exchanged by the heat conveying fluid. The facility allows simulating typical central heating systems characterized by several types of water radiators as heat delivery points and different distribution circuit topologies.

The paper describes in detail the INRIM thermo-hydraulic simulator, pointing out its main design features and metrological capabilities. Furthermore, the results of the analysis carried out on different heat metering approaches are discussed, focusing on the comparison between the innovative EcoThermo heat accounting method and conventional HCAs.

\section{The full-scale thermo-hydraulic simulator}

A fully-instrumented and hydraulically-reconfigurable central heating system simulator has been designed and built at INRIM in order to test the measurement capabilities of thermal energy measurement devices and heat cost allocation systems, in a set of heat transfer conditions that are representative of the ones experienced in real applications, as in 
residential room heating by means of water radiators. Figure 1 shows an overview of the thermal-hydraulic circuit of the central heating system simulator, which has been installed into a $300 \mathrm{~m}^{3}$ warehouse at INRIM.

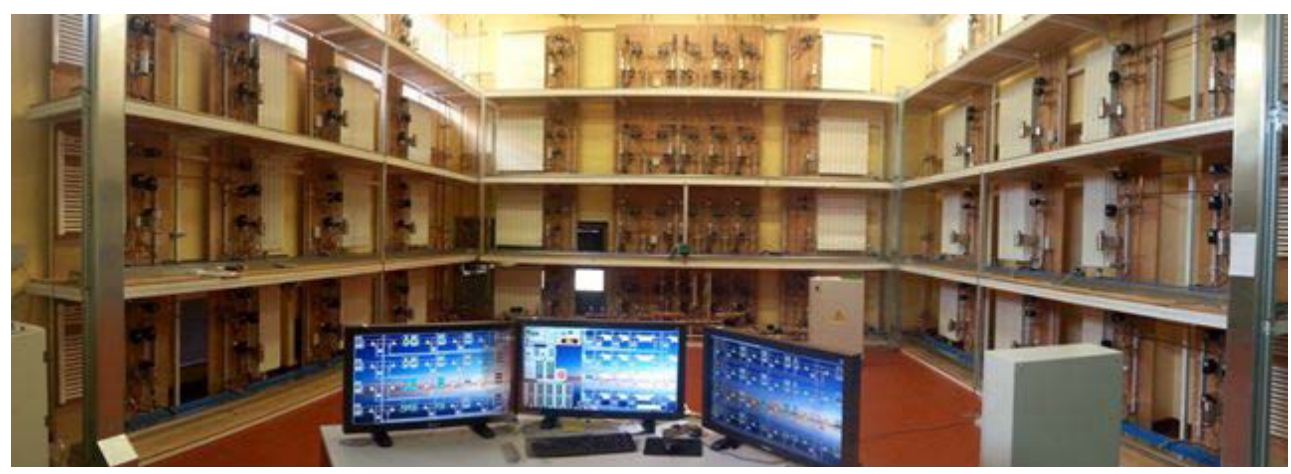

Fig. 1. Overview of the thermo-hydraulic circuit of the INRIM central heating system simulator.

The laboratory consists of 40 radiators of different shapes, hydraulic connections, dimensions and materials (20 aluminum, 14 tubular steel and 6 cast iron radiators), deployed on the vertical walls of the laboratory in aligned arrangement; namely, the vertical walls are subdivided into 4 floors, in order to simulate 8 living units with 5 radiators each, separated by shelves of about $0.8 \mathrm{~m}$ depth, which prevent the mutual thermal interaction between adjacent water radiators. The thermal-hydraulic circuit is automatically reconfigurable, by means of 180 motorized valves, which allow simulating different water distribution network topologies (vertical risers, horizontal connections in series or parallel).

A conventional natural gas condensation boiler (thermal power modulation of the burner ranging from about $10 \mathrm{~kW}$ to $50 \mathrm{~kW}$ ) and a centrifugal pump with electronic speed control are used for generating the desired water supply temperature, flow rate and pressure inside the thermal-hydraulic circuit. An adequate air exchange rate is ensured by a mechanical ventilation system (maximum air extraction of about $5200 \mathrm{~m}^{3} / \mathrm{h}$ ).

All the measurement signals are acquired and converted by a PLC, which also allows actuating the motorized valves for switching the hydraulic distribution modes and controlling the condensation boiler and the pump. The SCADA-HMI software Movicon ${ }^{\mathrm{TM}}$ enables to monitor and store the measurement data and to automatically control the operation of the central heating system. Furthermore, the SCADA enables the calculation of the thermal energy exchanged by each water radiator (Radiator Calculation Unit), implementing the reference IAPWS formulations for the assessment of the thermodynamic properties of water [19] and the time integration of the radiator thermal power.

The performance of heat cost allocation systems and heat metering devices can be evaluated at the INRIM central heating system test facility, by comparison against reference thermal energy measurements, provided at each heat delivery point. Namely, each water radiator of the thermal-hydraulic circuit is equipped with a SI-traceable direct heat meter, which provides the reference measurement of the thermal energy exchanged by the heat conveying fluid. In such a way, each water radiator represents a reference measurement system for thermal energy; furthermore, as far as the tests of heat accounting systems are concerned, the reference fractions of heat consumption associated to each water radiator can be obtained from the measurements provided by the radiator direct heat meters.

Every reference direct heat meter consists of an electromagnetic flow meter $(8 \mathrm{~mm}$ internal diameter), two Pt100 platinum resistance thermometers (3 $\mathrm{mm}$ stem diameter and $50 \mathrm{~mm}$ stem length) and a thermal energy calculation unit directly implemented on the 
SCADA software, which receives the converted measurement signals from the PLC (Figure 2).

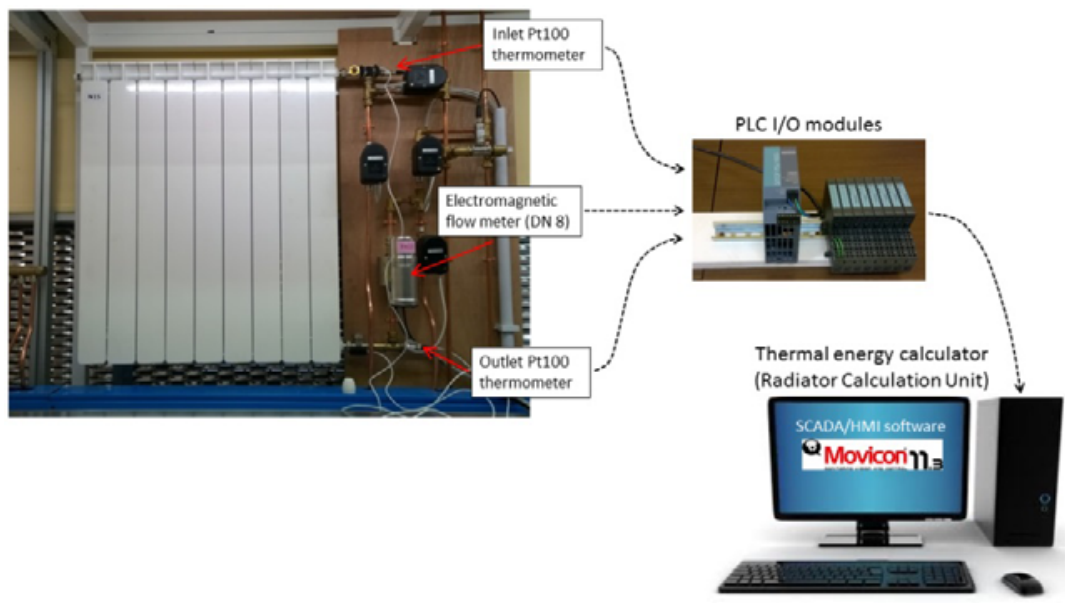

Fig. 2. Reference direct heat meter installed at a water radiator of the INRIM central heating system simulator.

The measurement of the overall water flow rate circulating in the hydraulic circuit is provided by an electromagnetic flow meter of $20 \mathrm{~mm}$ internal diameter, while the overall head loss through the circuit is obtained from the measurement of water pressure, provided by relative pressure transducers installed at the main supply and return pipe flows. Moreover, the head loss across each water radiator is measured by new differential pressure transducers, properly designed to compensate the effect of the water temperature difference between the inlet and outlet radiator flow sections on pressure difference measurement.

The measurement range and uncertainty for the reference measuring instruments used at the INRIM thermo-hydraulic simulator are listed in Table 1.

Table 1. Main characteristics of measuring instruments at the INRIM thermo-hydraulic simulator.

\begin{tabular}{|l|l|l|}
\hline & Range & $\begin{array}{l}\text { Expanded Uncertainty } \\
\mathbf{( 9 5 \%} \text { conf.int.) }\end{array}$ \\
\hline $\begin{array}{l}\text { Temperature measurement } \\
\text { chain (Pt100 sensor, 4-wire } \\
\text { shielded cable, PLC module) }\end{array}$ & from $0{ }^{\circ} \mathrm{C}$ to $90{ }^{\circ} \mathrm{C}$ & $0.06{ }^{\circ} \mathrm{C}$ \\
\hline \multirow{2}{*}{$\begin{array}{l}\text { Electromagnetic flow meters } \\
\text { (DN8) }\end{array}$} & from $90 \mathrm{~L} / \mathrm{h}$ to $1800 \mathrm{~L} / \mathrm{h}$ & $0.2 \%$ (of the measured value) \\
\cline { 2 - 3 } & from $20 \mathrm{~L} / \mathrm{h}$ to $90 \mathrm{~L} / \mathrm{h}$ & $\begin{array}{l}\text { from } 0.2 \%(\text { at } 90 \mathrm{~L} / \mathrm{h}) \text { to } \\
2 \%(\text { at } 20 \mathrm{~L} / \mathrm{h})\end{array}$ \\
\hline $\begin{array}{l}\text { Electromagnetic flow meters } \\
\text { (DN20) }\end{array}$ & from $500 \mathrm{~L} / \mathrm{h}$ to $11500 \mathrm{~L} / \mathrm{h}$ & $0.2 \%$ (of the measured value) \\
\hline Relative pressure transducers & $0 \div 5 \mathrm{bar}$ & $0.15 \%$ (of the full scale) \\
\hline $\begin{array}{l}\text { Differential pressure } \\
\text { transducers }\end{array}$ & $0 \div 0.5 \mathrm{bar}$ & $0.1 \%$ (of the full scale) \\
\hline
\end{tabular}

The uncertainty of radiator thermal power measurements, as given by the reference direct heat meters, results from the propagation of the uncertainties associated with the input quantities through the measurement model. In addition to the uncertainties reported in Table 1, the uncertainty of thermal power measurement also takes into account the stability 
of measurements at the test facility and the uncertainty related to the equation of state for the estimation of the thermodynamic properties of water [19, 20]. Figure 3 shows an example of the stability of reference flow rate measurements (Figure 3a) and inlet-outlet temperature difference measurements (Figure 3b), as obtained for a particular water radiator of the thermal-hydraulic circuit. In Figure $3 b$, the time trend of the reference temperature difference measurement and the corresponding relative standard deviations (green bars), evaluated during the time intervals characterized by stable temperature measurements, are shown.

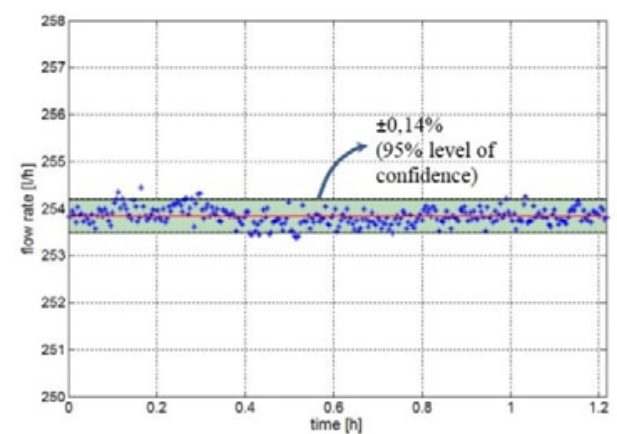

(a)

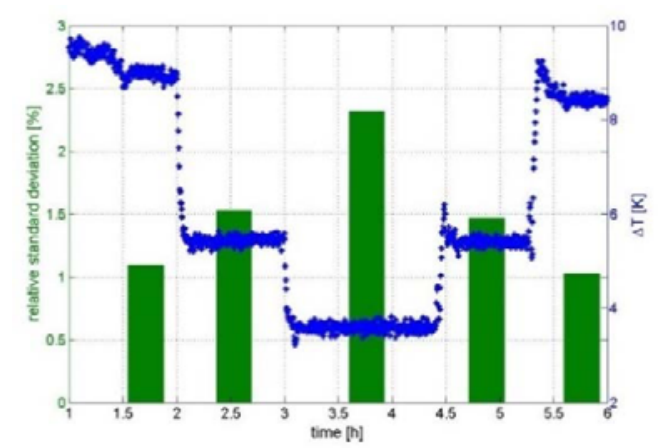

(b)

Fig. 3. (a) Stability of reference water flow rate measurements at a water radiator; (b) reference inletoutlet temperature difference measurements at a water radiator and corresponding relative standard deviations during the time periods characterized by stable temperature measurements.

The Monte Carlo Method has been used to evaluate the uncertainty associated with thermal power measurements, provided by the reference direct heat meters of the central heating system simulator, taking into account the uncertainty of the measuring instruments, the stability of measurements at the test facility and the uncertainty associated to the formulation of the water equation of state for the evaluation of the thermodynamic properties. Figure 4 shows the dependence of the relative standard uncertainty of thermal power measurement, with respect to the inlet-outlet water temperature difference, for a particular direct heat meter of the test facility.

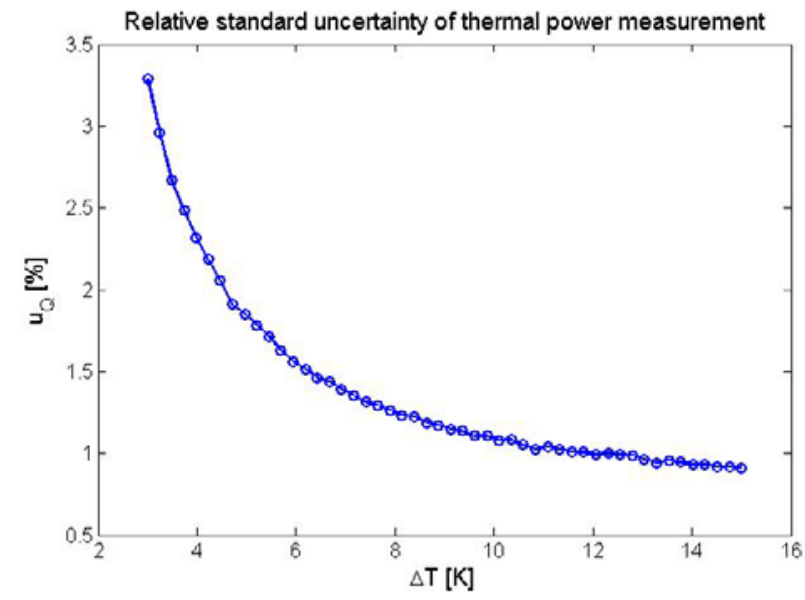

Fig. 4. Relative standard uncertainty associated with thermal power measurement provided by a particular reference direct heat meter at the INRIM central heating system simulator. 
The sub-assemblies of the reference direct heat meters, installed on each water radiator of the test facility, are periodically calibrated in order to ensure the metrological traceability of the corresponding thermal energy measurements.

\section{The EcoThermo heat accounting method}

The EcoThermo heat accounting method aims to directly evaluate the thermal energy exchanged by each water radiator of a central heating system by means of:

- the model-based estimation of radiator flow rates (EcoThermo virtual flow sensor);

- the measurement of the inlet and outlet water temperature at each radiator.

The EcoThermo virtual flow sensor allows estimating the flow rates circulating through the branches of a water distribution network, by solving the hydraulic model of the circuit. Namely, conservation of mass and momentum are applied, respectively, at the nodes and branches of the network and the resulting system of equations is solved in order to determine the distribution of water flow rates in the circuit.

As far as the hot water distribution networks of typical central heating systems are concerned, the EcoThermo model allows determining the water flow rates circulating through the open radiators, from the measurements of the overall water flow rate and pressure loss through the circuit, as provided by a flow meter (or a sufficient number of flow meters of different sizes according to the measurement range to be covered) and two pressure transducers installed at the main pipe flow in the boiler room (Figure 5).

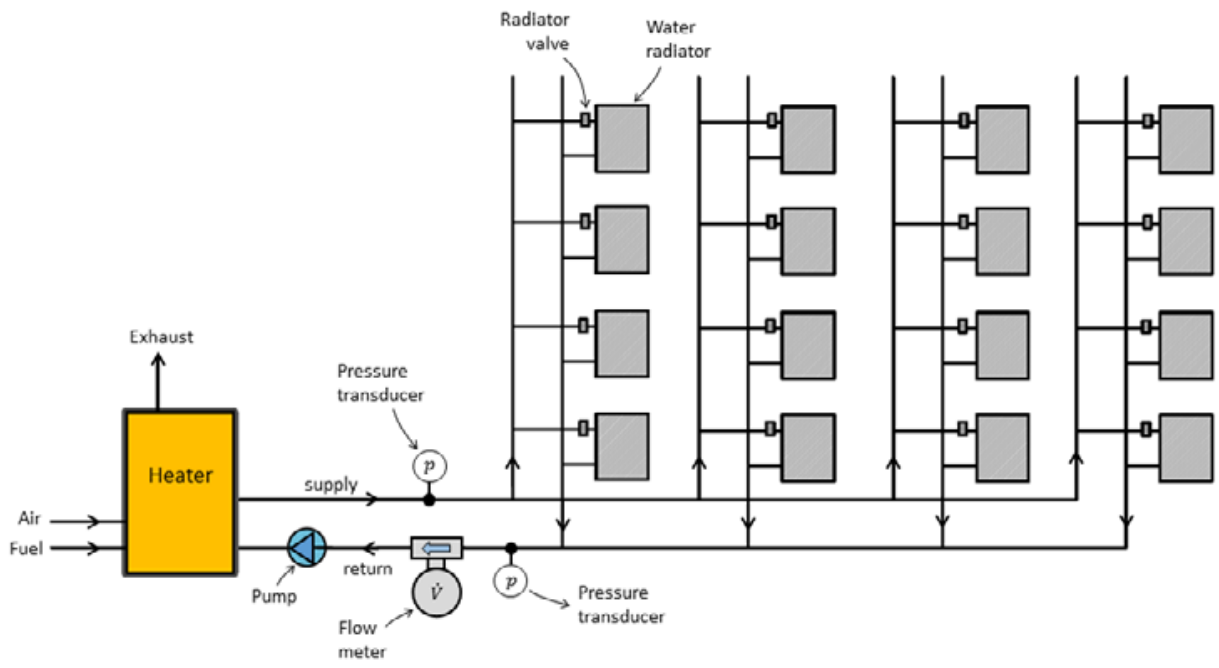

Fig. 5. Typical hot water distribution network of a central heating system (vertical distribution) with a flow meter and two pressure transducers installed at the main pipe flow.

Of course, the head loss characteristics of all the hydraulic elements and components of the circuit must be preliminarily determined. Along this line, in order to assess the radiator flow rates during a particular working condition of the central heating system, the EcoThermo model must receive, as input, also the opening degree of radiator valves, which is correlated to the corresponding pressure loss. The use of thermostatic valves could be more critical for the application of the EcoThermo virtual flow sensor, since the continuous 
modulation of the radiator flow rate, based on the desired indoor air temperature, would imply a more complex system for the measurement of the opening degree.

In the EcoThermo model, the total pressure loss between the inlet and outlet nodes of a generic branch $(\Delta p)$ is described by the following approximated relation:

$$
\Delta p=a \dot{V}^{b}
$$

where $\dot{V}$ is the volume flow rate and the parameters $a$ and $b$ are the characteristic hydraulic coefficients of the branch. Equation (1) can be considered as a generalized and approximated relation for the evaluation of the total pressure loss along a generic branch of the network. In Equation (1), unlike the Darcy-Weisbach relation for the assessment of continuous pressure losses, the constant multiplication factor $(a)$ does not consider the Reynolds dependence of the friction factor, in particular, for the laminar flow regime. The effect of the flow regime on pressure losses is taken into account by the constant volume flow rate exponent $(b)$, which, as well as the other characteristic hydraulic coefficient $(a)$, can be obtained by non-linear regression of measurement data for water volume flow rate and corresponding pressure loss, within a significant flow range, from the laminar to the turbulent regime.

A further approximation for the evaluation of the total pressure loss in a generic branch of the circuit can be carried out considering a quadratic dependence from the volume flow rate:

$$
\Delta p=\beta \dot{V}^{2}
$$

where the branch is described by a single characteristic hydraulic coefficient $(\beta)$, which must be determined by regression analysis of experimental data. Since the hydraulic coefficient $(\beta)$ is a constant parameter, not depending on the Reynolds number of the pipe flow, Equation (2) better applies to the turbulent flow regime.

The electrical analogy can be effectively exploited for describing the hydraulic circuit, considering the total pressure loss and the mass flow rate, respectively, as the voltage and the current in an electric circuit. In such a way, the conservation of mass at the nodes of the hydraulic network and the conservation of momentum at the branches can be approximatively described, in the electrical analogy, by means of the Kirchhoff's circuit laws. The hydraulic resistance of each branch can be represented by means of a currentdependent electrical resistance and, consequently, the hydraulic circuit can be described as a non-linear electric circuit. Moreover, each branch containing a water radiator with the corresponding valve can be considered as a rheostat in the electrical analogy, since the function of radiator valves is to modulate the water flow rates by changing their hydraulic resistance.

An important issue for the EcoThermo virtual flow sensor is the preliminary identification of the characteristic hydraulic parameters of all the branches of the hot water distribution network, which is fundamental to determine the water flow rates circulating through each radiator, during the normal operation of the central heating system. This is accomplished by a parameter identification procedure, which can be applied to the most common hot water distribution networks, without knowing, a priori, the hydraulic scheme of the circuit, lengths and diameters of pipe branches and head loss characteristics of hydraulic components (junctions, valves, etc.).

The procedure for the parameter identification of the hydraulic circuit is the core of the EcoThermo virtual flow sensor and consists of the characterization of the minimum number of hydraulic loops or sub-circuits, whose inlet and outlet flow sections coincide with the main supply and return water flows from the pump. Namely, the equivalent pressure loss 
coefficients of each sub-circuit are estimated by non-linear regression analysis of the measurements of water flow rate and corresponding pressure loss at ambient temperature conditions, as provided by a fixed volumetric flow meter (or a sufficient number of flow meters of different sizes according to the measurement range to be covered) and two pressure transducers installed at the main supply and return pipe flows in the boiler room. Thus, since the equivalent pressure loss coefficients of each sub-circuit are correlated to the hydraulic characteristic coefficients of the branches that make up the particular loop, the identification of all the parameters of the water distribution network is possible.

The use of a suitable pump equipped with an inverter or other flow rate control systems is necessary in order to generate a representative set of water flow rates and head losses for the hydraulic characterization of the sub-circuits.

It is worth observing that, if Equation (2) is used for describing the functional dependence between volume flow rate and total pressure loss, then it is possible to solve the series and parallel connections between hydraulic resistances, obtaining equivalent characteristic hydraulic coefficients. Namely, considering a constant temperature water flow, the series connection between two hydraulic resistances results in the following equivalent characteristic coefficient:

$$
\beta_{e q, S}=\beta_{1}+\beta_{2}
$$

while, for the parallel connection:

$$
\beta_{e q, P}=\frac{\beta_{1} \beta_{2}}{\left(\sqrt{\beta_{1}}+\sqrt{\beta_{2}}\right)^{2}}
$$

Thus, for a generic water distribution network or sub-circuit, using Equations (3-4), it is possible to determine an equivalent characteristic hydraulic coefficient, which is function of the characteristic pressure loss coefficients of the branches:

$$
\beta_{\text {eq }}=g\left(\beta_{1}, \beta_{2}, \ldots, \beta_{n}\right)
$$

The functional dependence between the total pressure loss $\left(\Delta p_{t o t}\right)$ and the overall volume flow rate $\left(\dot{V}_{t o t}\right)$ through a generic hydraulic network or sub-circuit can be expressed as follows:

$$
\Delta p_{t o t}=\beta_{e q} \dot{V}_{t o t}^{2}
$$

The value of the equivalent characteristic coefficient $\left(\beta_{e q}\right)$ can be determined by regression analysis of the measurement data for total pressure loss $\left(\Delta p_{\text {tot }}\right)$ and overall volume flow rate $\left(\dot{V}_{t o t}\right)$, at ambient temperature conditions for the water flow, according to the phenomenological relation given by Equation (6). Figure 6 shows an example of the results of the regression analysis, carried out for a particular sub-circuit of a water distribution network. 


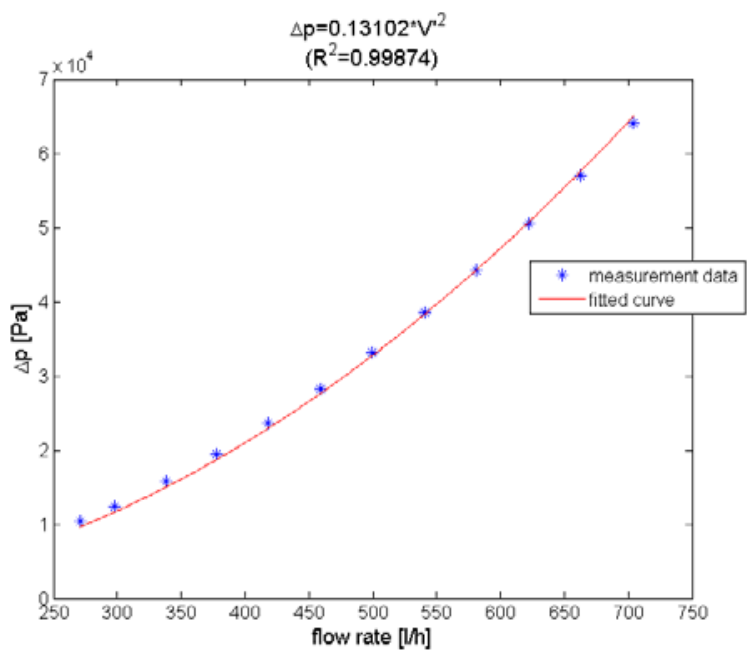

Fig. 6. Example of regression analysis for the pressure loss characteristic of a particular sub-circuit of a water distribution network.

In order to determine the characteristic hydraulic coefficients of all the branches of a generic network, a minimum number of sub-circuits, equal to the number of the unknown parameters of the branches, should be characterized in terms of equivalent pressure loss coefficients, by means of regression analysis of measurement data. Thus, the parameter identification of the branches is carried out by solving the non-linear system of equations, made up by the expressions that relates the equivalent characteristic coefficients of the subcircuits, whose inlet and outlet flow sections coincide with the main supply and return water flows from the pump, to the unknown characteristic hydraulic coefficients of the branches.

$$
\left\{\begin{array}{c}
\beta_{e q, 1}=g_{1}\left(\beta_{1}, \beta_{2}, \ldots, \beta_{n}\right) \\
\beta_{e q, 2}=g_{2}\left(\beta_{1}, \beta_{2}, \ldots, \beta_{n}\right) \\
\vdots \\
\beta_{e q, n}=g_{n}\left(\beta_{1}, \beta_{2}, \ldots, \beta_{n}\right)
\end{array}\right.
$$

The choice of the sub-circuits to be characterized for the identification of the hydraulic characteristic coefficients of the branches is based on the selection of the hydraulic loops, whose inlet and outlet flow sections coincide with the supply and return water flows from the pump. The selected sub-circuits must allow identifying all the hydraulic branches of the network and include different numbers of water radiators. For each hydraulic loop, a representative set of overall water flow rates and pressure losses is generated by the pump, at ambient water temperature, in order to determine the equivalent characteristic hydraulic coefficient of the sub-circuit by regression analysis.

Once the sub-circuits have been characterized and the pressure loss coefficients of the branches have been identified by solving the non-linear system of equations described by Equation (7), the radiator flow rates can be estimated for any operating condition of the central heating system. Namely, radiator flow rates are evaluated by solving the hydraulic model of the hot water distribution network, made up by the equations for mass conservation at the nodes and momentum conservation at the branches, taking as inputs the measurements of the overall water flow rate and pressure loss in the circuit and the opening degree of radiator valves. 
An important requirement for the EcoThermo model is the knowledge of the hydraulic characteristics of radiator inlet valves and automatic balancing valves, as function of their opening degree, in order to evaluate the additional concentrated pressure loss for the corresponding branches during the operation of the central heating system. Of course, all the manual valves, like radiator "lockshield" valves (the ones at the opposite end of the radiator with respect to the inlet valves), must be kept in the same opening position as during the parameter identification procedure, in order to avoid errors in the estimation of radiator flow rates.

The tests for the validation of the EcoThermo virtual flow sensor have been carried out on a wide set of distribution circuit topologies and operating conditions at the INRIM central heating system test facility, in order to significantly evaluate the performance of the EcoThermo virtual flow sensor. The results of a test case for the experimental validation of the EcoThermo model are presented, taking into account the Equation (2) for the volume flow rate dependence of the total pressure loss along the network branches and the parameter identification procedure described above.

A set of 14 water radiators, which consists of eleven aluminum, two cast iron and one tubular steel radiators distributed on four different risers, as shown in Figure 7, has been selected for the validation of the EcoThermo virtual flow sensor. It is worth observing that such a portion of the INRIM central heating system test facility has not been hydraulically balanced for the tests; this means, for instance, that water flow rates of radiators installed on the same vertical column, are different as function of the position of radiators along the riser.

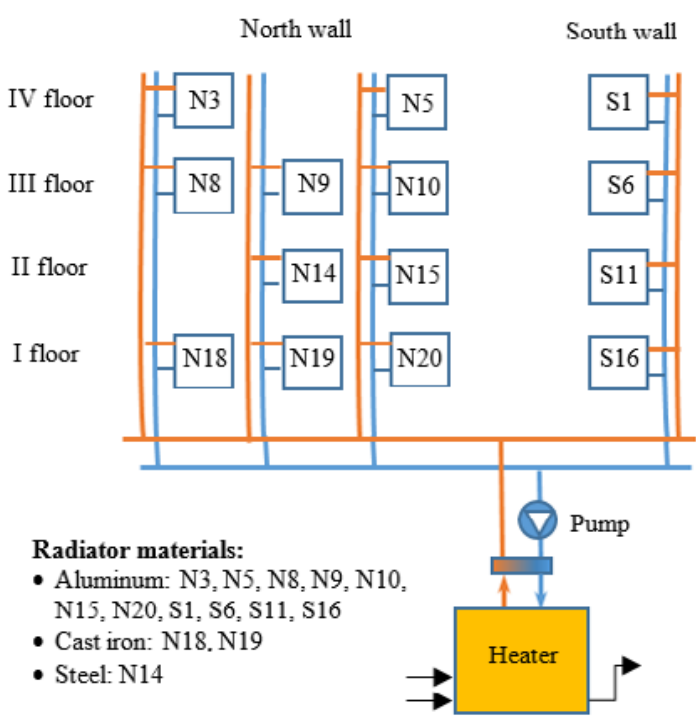

Fig. 7. Selected set of water radiators for the validation of the EcoThermo virtual flow sensor at the INRIM thermo-hydraulic simulator.

First, the parameter identification for the water distribution network of the INRIM central heating system test facility, made up by the 14 selected radiators, has been carried out. A minimum number of 27 branches or unknown hydraulic resistances $(\beta)$ can be used for describing the water distribution network, as depicted in Figure 8. 


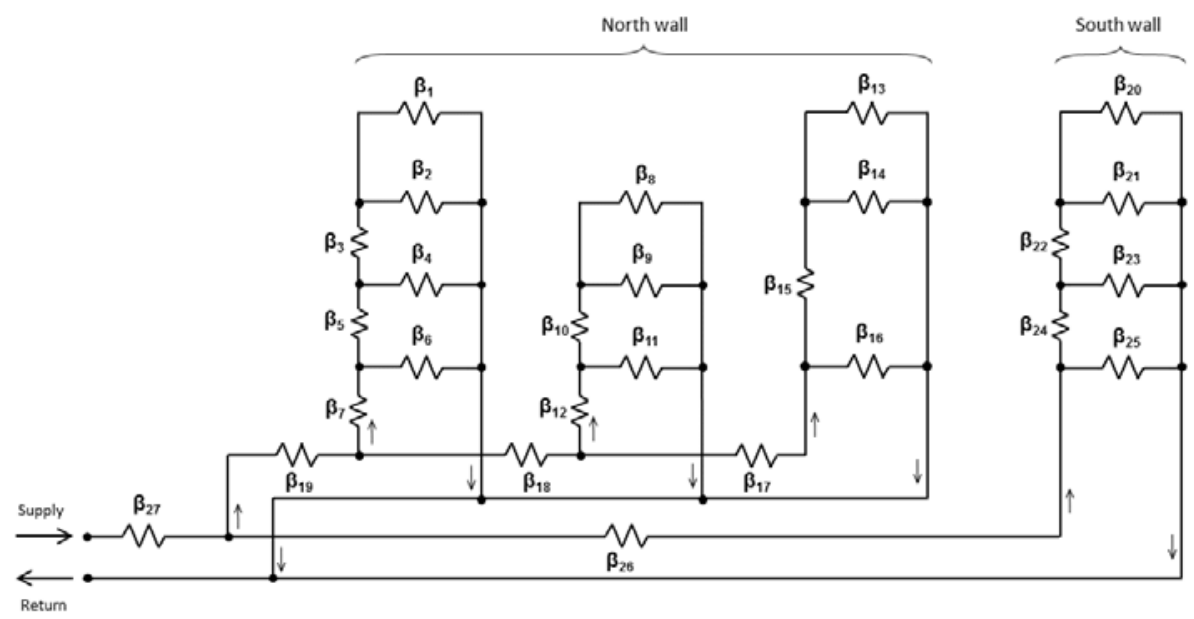

Fig. 8. Electrical analogy of the hot water distribution network consisting of the set of selected radiators.

In order to identify the characteristic hydraulic coefficients $(\beta)$ of the branches, 27 subcircuits have been properly selected and characterized by regression analysis of volume flow rate and pressure loss measurement data, at ambient water temperature conditions. A significant set of water flow rates and head losses have been generated by the centrifugal pump and its flow control system, while measurements have been provided by two electromagnetic flow meters of different sizes $(20 \mathrm{~mm}$ and $8 \mathrm{~mm}$ internal diameters $)$ and two pressure transducers installed at the main pipe flow.

The identification of the characteristic hydraulic coefficients of the 27 branches of the hot water distribution network has been carried out by solving the non-linear system of equations as given by Equation (7). The latter is made up by the expressions that relate the equivalent hydraulic coefficients of the 27 sub-circuits to the characteristic hydraulic coefficients of the branches.

Figure 9 shows the characteristic hydraulic coefficients of the 27 network branches, as obtained from the EcoThermo parameter identification procedure. Two distinct groups of characteristic coefficients can be observed: the one related to radiator branches (branches including a water radiator) and the one associated to pipe branches.

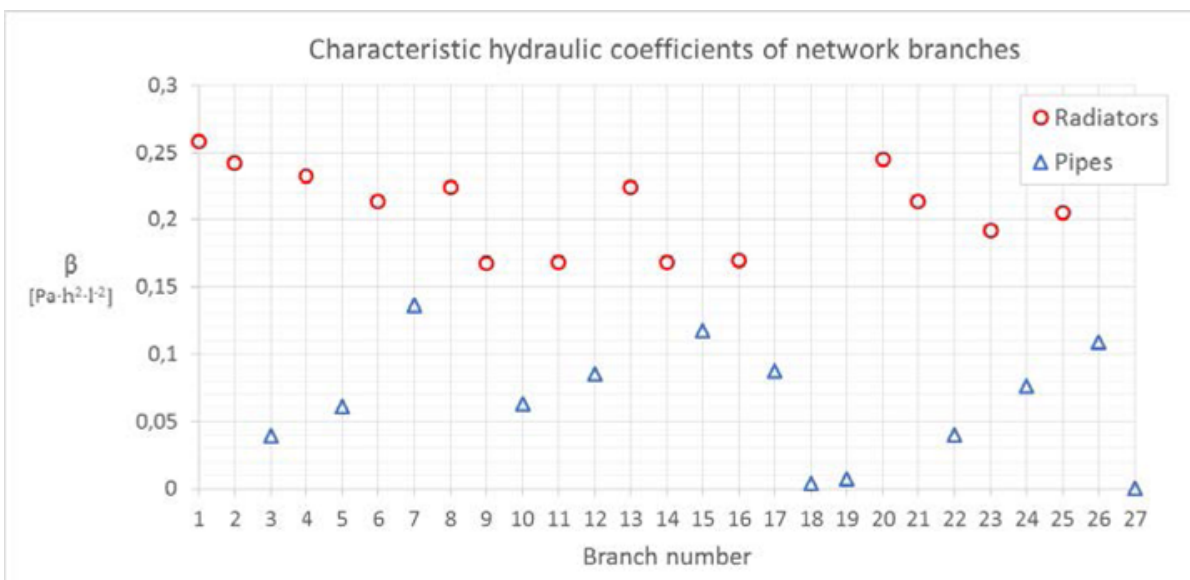

Fig. 9. Characteristic hydraulic coefficients of "radiator branches" and "pipe branches". 
The accuracy of the EcoThermo virtual flow sensor has been evaluated under different operating conditions for the selected set of water radiators of the INRIM thermo-hydraulic simulator shown in Figure 7. In particular, the results of the validation of the virtual flow sensor presented herein are related to a water distribution circuit consisting of 9 water radiators $(\mathrm{N} 20, \mathrm{~N} 10, \mathrm{~N} 5, \mathrm{~N} 19, \mathrm{~N} 9, \mathrm{~N} 8, \mathrm{~N} 3, \mathrm{~S} 16, \mathrm{~S} 1)$, which did not constitute any of the 27 sub-circuits used for the parameter identification procedure. Figure 10 shows the network configuration considered for the validation test case; the test has been carried out at ambient water temperature conditions (heater off) for different overall water flow rates and the radiator valves were kept in their fully-open position.

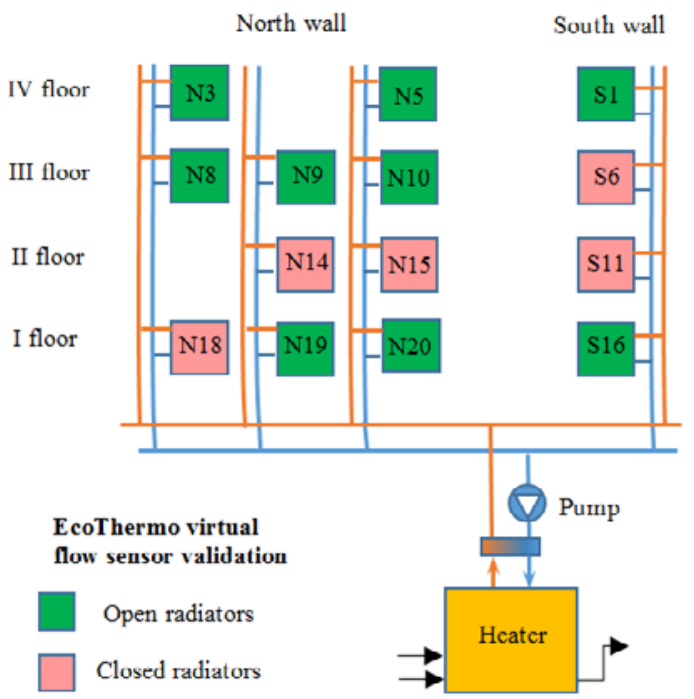

Fig. 10. Validation test case: configuration of the hydraulic network.

In Table 2 , the reference measurements of radiator flow rates $\left(\dot{V}_{i, R E F}\right)$ are listed for such a test case. The seven measurement points are related to different overall water flow rates generated by the pump, at ambient water temperature conditions.

Table 2. Validation test case: reference measurements of radiator flow rates.

\begin{tabular}{|c|c|c|c|c|c|c|c|c|c|c|c|}
\hline \multirow{2}{*}{\multicolumn{2}{|c|}{$\begin{array}{c}\dot{V}_{i, R E F} \\
{[\mathbf{L} / \mathbf{h}]}\end{array}$}} & \multicolumn{9}{|c|}{ Radiators } & \multirow{3}{*}{\begin{tabular}{|l} 
TOT \\
671.1 \\
\end{tabular}} \\
\hline & & \multirow{2}{*}{$\begin{array}{l}\mathbf{N 2 0} \\
79.9 \\
\end{array}$} & \multirow{2}{*}{$\begin{array}{l}\text { N10 } \\
43.4 \\
\end{array}$} & \multirow{2}{*}{$\begin{array}{c}\text { N5 } \\
40.3 \\
\end{array}$} & \multirow{2}{*}{$\begin{array}{l}\text { N19 } \\
104.0\end{array}$} & \multirow{2}{*}{$\begin{array}{c}\text { N9 } \\
75.0\end{array}$} & \multirow{2}{*}{$\begin{array}{c}\text { N8 } \\
71.3\end{array}$} & \multirow{2}{*}{$\begin{array}{c}\text { N3 } \\
61.7\end{array}$} & \multirow{2}{*}{$\frac{\text { S16 }}{114.2}$} & \multirow{2}{*}{$\begin{array}{c}\text { S1 } \\
81.2\end{array}$} & \\
\hline \multirow{7}{*}{ 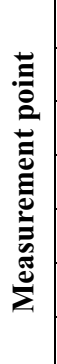 } & 1 & & & & & & & & & & \\
\hline & 2 & 110.0 & 59.5 & 56.6 & 144.0 & 104.0 & 100.2 & 84.7 & 156.8 & 112.9 & 928.6 \\
\hline & 3 & 134.9 & 73.4 & 70.0 & 176.5 & 129.3 & 124.3 & 105.1 & 191.4 & 139.7 & 1144.6 \\
\hline & 4 & 159.6 & 87.7 & 83.1 & 209.0 & 154.8 & 148.2 & 126.0 & 226.1 & 166.8 & 1361.2 \\
\hline & 5 & 182.0 & 100.8 & 95.8 & 238.8 & 178.1 & 170.2 & 145.5 & 257.9 & 191.8 & 1560.9 \\
\hline & 6 & 204.5 & 114.1 & 108.8 & 268.9 & 201.8 & 192.4 & 165.2 & 289.6 & 217.5 & 1762.9 \\
\hline & 7 & 175.2 & 96.9 & 92.1 & 229.8 & 171.2 & 163.6 & 139.8 & 248.2 & 184.7 & 1501.7 \\
\hline
\end{tabular}


For each measurement point, the percentage relative deviations between the radiator flow rates estimated by the EcoThermo virtual flow sensor $\left(\dot{V}_{i}\right)$ and the corresponding reference measurements provided by the volume flow meters $\left(\dot{V}_{i, R E F}\right)$ have been evaluated.

$$
\varepsilon_{\dot{V}, i}=100 \frac{\dot{V}_{i}-\dot{V}_{i, R E F}}{\dot{V}_{i, R E F}}
$$

Figure 11 shows the results of the validation, in terms of percentage relative deviations of the EcoThermo virtual flow sensor, with respect to the reference measurements of radiator flow rates.

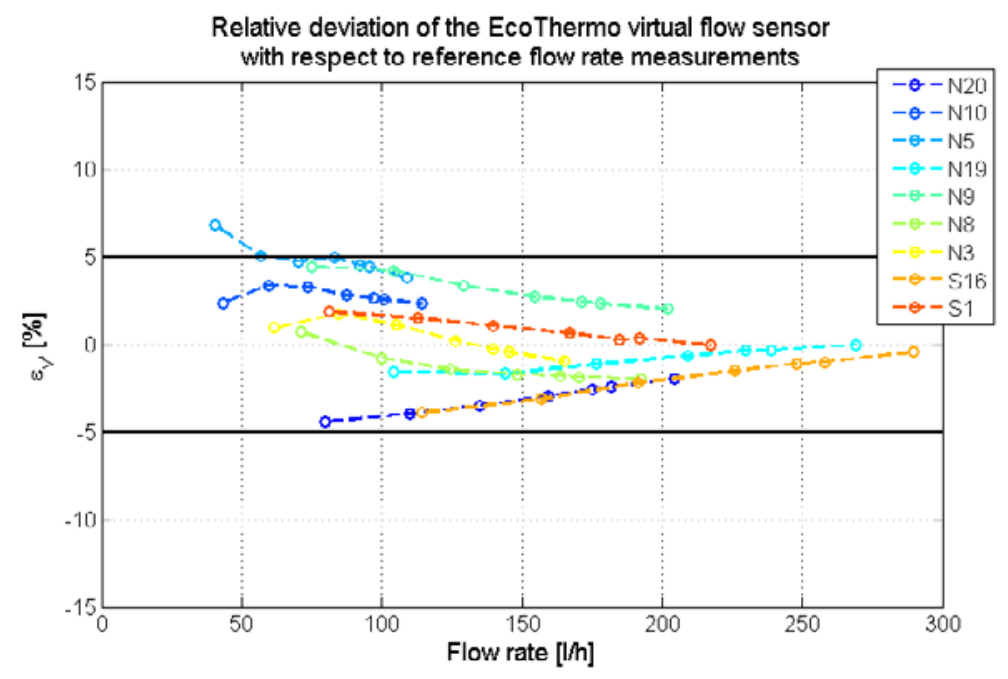

Fig. 11. Validation test case: relative deviations of the EcoThermo virtual flow sensor, with respect to the reference measurements of radiator flow rates, as function of radiator flow rates.

As can be observed from Figure 11, the relative deviations of the EcoThermo virtual flow sensor are higher for lower water flow rates, mainly because of the approximated model for the description of the volume flow rate dependence of pressure loss along the network branches. As discussed above, such a model better applies to the turbulent flow regime and its use for the description of laminar or transitional flow conditions, which may occur at the network branches, can lead to wrong flow rate estimations. Moreover, concerning water flow rates lower than $90 \mathrm{~L} / \mathrm{h}$, higher uncertainties for reference volume flow metering (up to $2 \%$ at $20 \mathrm{~L} / \mathrm{h}$ ) should be taken into account.

\section{Validation of the EcoThermo method and comparison with conventional HCAs}

The EcoThermo virtual flow sensor, in addition to the measurements of the inlet-outlet water temperature difference at each heating body, allows providing a direct evaluation of the thermal energy exchanged by water radiators. In such a way, the problems related to the installation effects, which significantly affect the accuracy of indirect methods for the evaluation of the heat output of water radiators, can be avoided and the resulting heat cost allocation would be safe from installation effects. 
The EcoThermo heat accounting method has been tested at the INRIM central heating system simulator and compared against conventional HCAs (Figure 12).

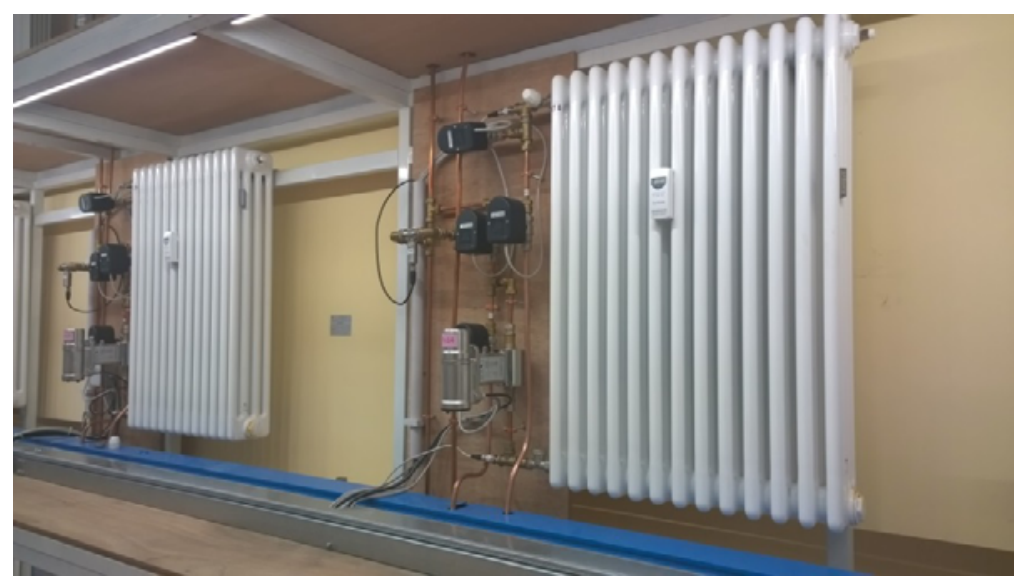

Fig. 12. HCAs installed at the INRIM thermo-hydraulic simulator.

A set of 10 water radiators, consisting of seven aluminum, two cast iron and one tubular steel radiators distributed on four different risers, as shown in Figure 13, has been selected for the test.

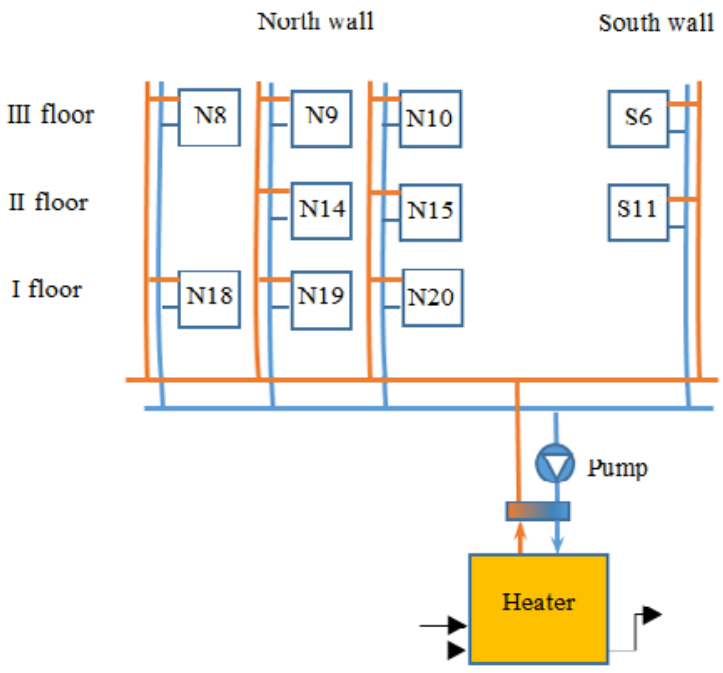

Fig. 13. Selected set of water radiators for the validation of the EcoThermo heat accounting method and the comparison against conventional HCAs.

The pump and the heater have been programmed to feed the 10 radiators of the network with the desired water flow rate and temperature, and the motorized radiator valves have been automatically controlled to set the desired opening/closing times.

The task for the EcoThermo heat accounting method and the set of HCAs is to provide the individual percentage fractions of thermal energy consumption for each water radiator, defined as: 


$$
f_{i}=100 \frac{Q_{i}}{\sum_{j=1}^{10} Q_{j}}
$$

where $Q_{i}$ is the thermal energy exchanged by the $i$-th water radiator, as calculated by the EcoThermo heat accounting model during the test, or the number of allocation units totalized by the $i$-th HCA installed on the $i$-th water radiator during the same time. The summation of the radiator thermal energies estimated by the EcoThermo method, or the summation of the radiator allocation units provided by HCAs applies, of course, to the set of 10 water radiators selected for the test.

The two heat accounting systems have been compared between each other by evaluating, for each water radiator, the deviation between the estimated fraction of thermal energy consumption and the one obtained from the measurements provided by reference direct heat meters and calculated according to Equation (9) as well. The percentage relative deviations with respect to the reference measurements of the individual fractions of heat consumption $\left(f_{i, R E F}\right)$ can be expressed as follows:

$$
\varepsilon_{f_{i}}=100 \frac{f_{i}-f_{i, R E F}}{f_{i, R E F}}
$$

HCAs have been programmed using the radiator characteristic coefficients listed in Table 3 (radiator nominal thermal power and exponent according to the EN 442 standard) and the rating factors for the HCA-radiator coupling provided by the manufacturer, according to the EN 834 standard [9].

Table 3. Characteristic coefficients of water radiators.

\begin{tabular}{|c|c|c|c|}
\hline Radiator type & $\begin{array}{c}\text { Number of } \\
\text { elements }\end{array}$ & $\begin{array}{c}\text { Nominal thermal } \\
\text { power of a single } \\
\text { element at } \Delta \mathbf{T}=\mathbf{5 0} \\
\left.\dot{\boldsymbol{q}}_{\boldsymbol{N 5 0}} \mathbf{~} \mathbf{C}\right]\end{array}$ & $\begin{array}{c}\text { Exponent } \\
(\boldsymbol{n})\end{array}$ \\
\hline Aluminum radiators & 9 & 163 & 1.359 \\
\hline Cast iron radiators & 10 & 142.7 & 1.3679 \\
\hline Tubular steel radiators & 13 & 114 & 1.28 \\
\hline
\end{tabular}

The accuracy of the EcoThermo heat accounting method has been evaluated taking into account the error on radiator flow rate estimation only, assuming the water temperature measurements at the inlet-outlet radiator flow sections equal to the corresponding temperature measurements provided by reference Pt100 platinum resistance thermometers.

The experiment for testing the EcoThermo heat accounting method and the conventional HCA system is characterized by the following operating conditions:

- balanced hydraulic network: the thermal-hydraulic circuit has been preliminarily balanced, in order to obtain a uniform flow rate distribution among the water radiators, and the parameter identification procedure of the EcoThermo virtual flow sensor has been carried out, in order to characterize the hydraulic branches of the network before starting the heat accounting test;

- automatic control of the opening/closing time of radiator valves: the motorized ONOFF valves of the water radiators installed on the three floors of the thermohydraulic network (Figure 13) are preliminarily programmed in terms of 
opening/closing times, simulating typical daily occupancy behaviours, as shown in Figure 14;

- constant water supply temperature and constant pump speed: the heater is set to ensure a constant hot water supply temperature of $65^{\circ} \mathrm{C}$, and the pump is set to operate at $45 \%$ of its maximum speed (the heater is ensured to operate within its thermal power modulation range, even in the case of operation with a small number of open radiators, by dissipating the excess heat);

- compensation of transient heat transfer conditions associated to the heating up and cooling down of radiator surfaces: the test is designed in order to allow the comparison between the outputs of indirect heat accounting methods (HCAs) and reference direct heat metering;

- long-time duration of the test: the test is characterized by long-time recording, such that the resolution error of the $10 \mathrm{HCAs}$ becomes negligible if compared to the corresponding amount of totalized allocation units.

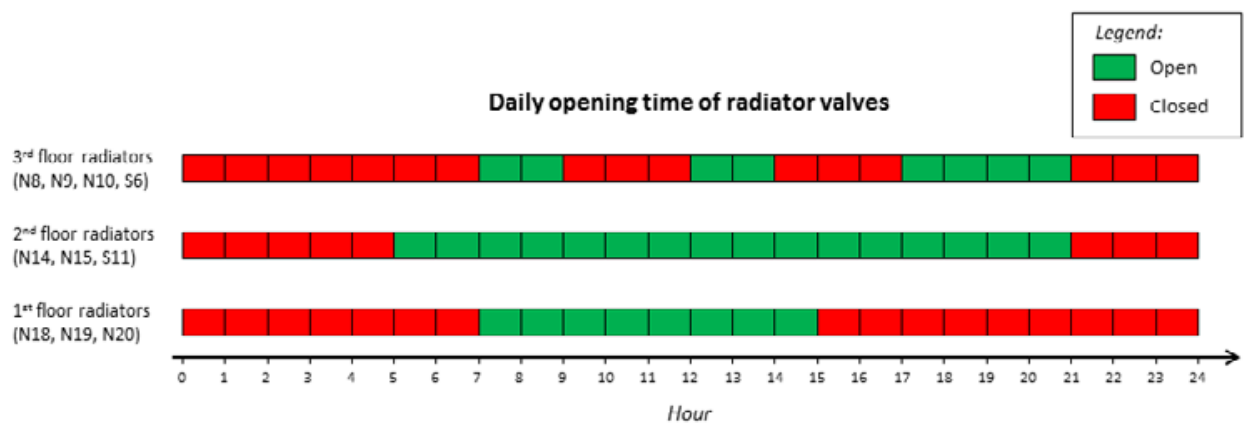

Fig. 14. Daily opening time of radiator valves programmed for the heat accounting test.

Figure 15 shows the time trend of the indoor air temperature measurements during the test, as given by five Pt100 platinum resistance thermometers installed at different heights inside the laboratory in proximity of the heating surfaces of the radiators. The time evolution follows the programmed opening/closing times of water radiators and highlights the vertical stratification of air temperature inside the laboratory.

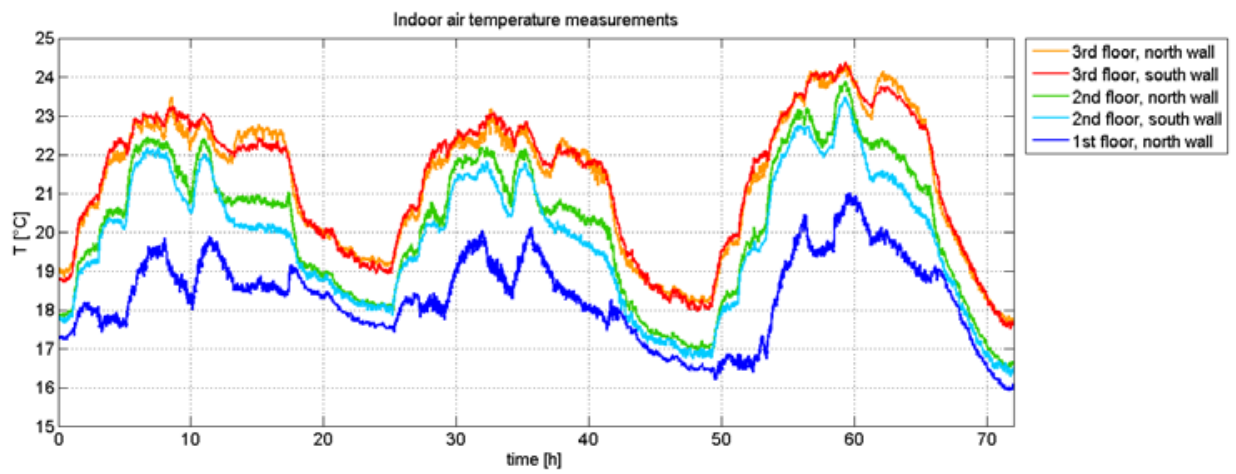

Fig. 15. Indoor air temperature measurements during the test.

The test conditions are such that the radiator water flow rates range from $70 \mathrm{~L} / \mathrm{h}$ to 130 $\mathrm{L} / \mathrm{h}$, depending on the hydraulic circuit configuration defined by the programmed daily opening time of radiator valves, while the inlet-outlet water temperature differences at the 
radiators range from $8{ }^{\circ} \mathrm{C}$ to $15{ }^{\circ} \mathrm{C}$, according to the type of heating body and the heat transfer conditions.

Figure 16 shows the results of the test in terms of percentage fractions of radiator thermal energy consumptions, as given by the reference direct heat meters, the EcoThermo heat accounting method and the HCAs.

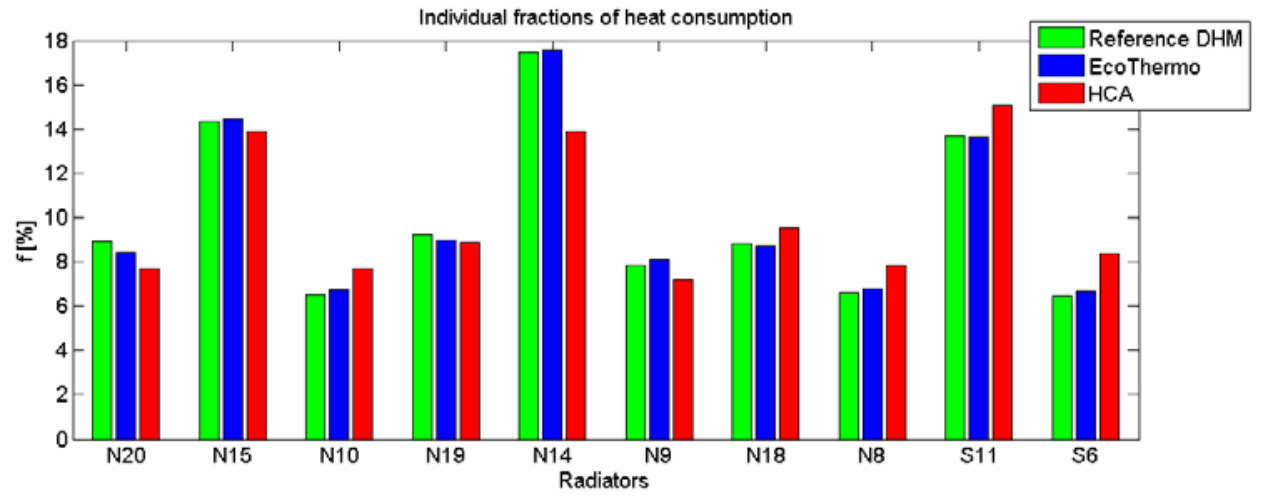

Fig. 16. Fractions of radiator heat consumption.

The percentage relative deviations of the individual fractions of radiator heat consumption with respect to the reference ones obtained by direct heat metering have been evaluated for the EcoThermo heat accounting method and the HCAs; the results are shown in Figure 17.

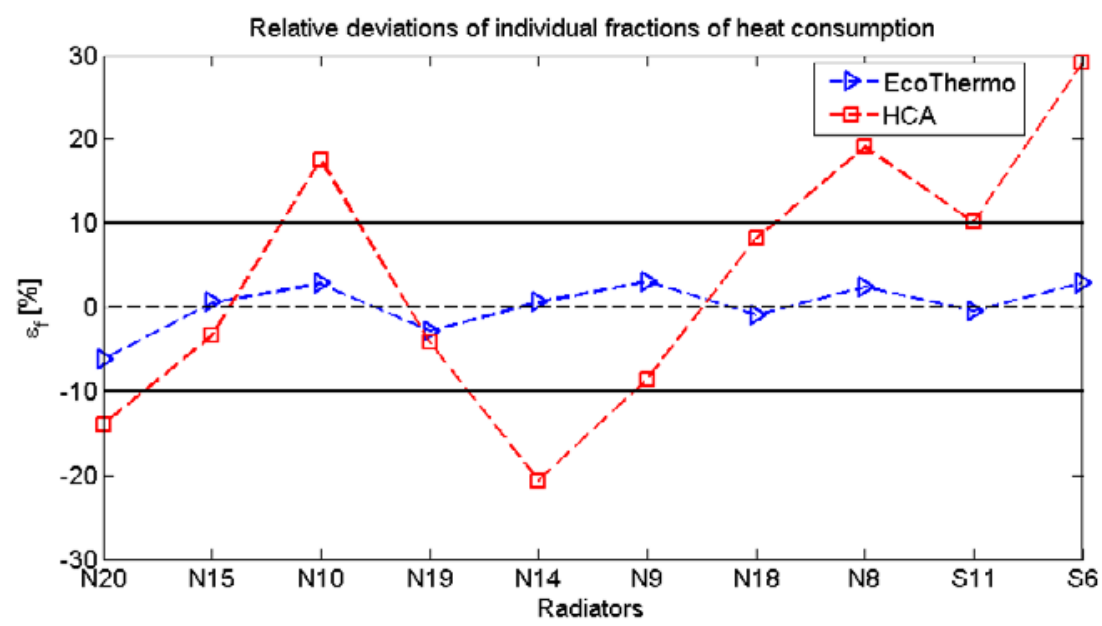

Fig. 17. Percentage relative deviations of the fractions of radiator heat consumption estimated by the EcoThermo heat accounting method and the HCA system, with respect to the reference ones evaluated by direct heat metering.

Unlike HCAs, the EcoThermo heat accounting method is not affected by the installation effects occurring at the water radiators of the INRIM thermo-hydraulic simulator, since it is based on the direct estimation of the thermal energy exchanged by the heat conveying fluid. As far as the EcoThermo heat accounting method is concerned, the percentage relative deviations on the fractions of heat consumption settle within the $\pm 6 \%$ band for all the water 
radiators under test, while, concerning the system of HCAs, higher values for the percentage deviations of individual fractions of heat consumption (even up to $30 \%$ ) have been obtained, confirming the strong influence of radiator installation effects on the accuracy of these kinds of indirect heat accounting systems.

\section{Conclusions}

The INRIM thermo-hydraulic simulator has allowed testing different heat accounting methods under actual operating conditions.

The knowledge of the contribution of the different installation effects occurring at water radiators in residential heating applications on the accuracy of indirect heat accounting systems, like the ones based on the use of HCAs, is a key point for the correct evaluation of the performances of such devices as far as heat cost allocation is concerned. The tests carried out at the INRIM thermo-hydraulic simulator have pointed out the expected heat cost allocation errors associated to the use of HCAs in a "vertical" hot water distribution network (vertical risers central heating plant configuration) consisting of 10 water radiators of different types, materials and installation conditions. Namely, high values of the percentage relative deviations with respect to the reference fractions of radiator heat consumption, even up to $30 \%$, have been obtained for HCAs.

The accuracy of the heat cost allocation provided by HCAs has been compared with the performance of the innovative EcoThermo heat accounting method, which is based on the estimation of radiator flow rates by the solution of the hydraulic model of the hot water distribution network. The accuracy of the EcoThermo method has been evaluated taking into account the error on radiator flow rate estimation only, assuming the water temperature measurements at the inlet-outlet radiator flow sections equal to the corresponding temperature measurements provided by reference Pt100 platinum resistance thermometers. The results of the tests have confirmed the independence of the EcoThermo method from the different installation effects occurring at water radiators. Moreover, the percentage relative deviations of the fractions of radiator heat consumption provided by EcoThermo, with respect to the reference heat cost allocation obtained by direct heat metering, have been observed to settle within the $\pm 6 \%$ band for all the water radiators under test, pointing out the effectiveness of the hydraulic model for the estimation of radiator flow rates.

Acknowledgments: The authors would like to thank Termoform Srl for providing the set of HCAs for the test, Federico Bari and Riccardo Tisseur for their fundamental contribution to the development and the improvement of the EcoThermo heat accounting method.

\section{References}

1. Buildings - European Commission. Available online: https://ec.europa.eu/energy/en/topics/energy-efficiency/buildings

2. Directive $2012 / 27 /$ EU of The European Parliament and of the Council of 25 October 2012 on energy efficiency, amending Directives 2009/125/EC and 2010/30/EU and repealing Directives 2004/8/EC and 2006/32/EC, Official Journal of the European Union n. L $315 / 1$ of the 14.11 .2012

3. Decreto Legislativo 4 luglio, n. 102 "Attuazione della direttiva 2012/27/UE sull'efficienza energetica, che modifica le direttive 2009/125/CE e 2010/30/UE e abroga le direttive 2004/8/CE e 2006/32/CE", Gazzetta Ufficiale n. 165 del 18/7/2014

4. OIML R 75-1, Heat Meters - Part 1: General Requirements, International Organization of Legal Metrology, Paris, 2002 
5. EN 1434-1, Heat Meters - Part 1: General Requirements, European Committee for Standardization, Brussels, 2007

6. Directive 2004/22/EC of the European Parliament and of the Council of 31 March 2004 on measuring instruments. Official Journal of the European Union

7. EN 442-1 Radiators and Convectors - Part 1: Technical Specification and Requirements; European Committee for Standardization: Brussels, Belgium, 2014

8. EN 442-2 Radiators and Convectors - Part 2: Test Methods and Rating; European Committee for Standardization: Brussels, Belgium, 2014

9. EN 834 Heat Cost Allocators for the Determination of the Consumption of Room Heating Radiators. Appliances with Electrical Energy Supply; European Committee for Standardization: Brussels, Belgium, 2013

10. UNI/TR 11388 Sistemi di Ripartizione Delle Spese di Climatizzazione Invernale Utilizzante Valvole di Corpo Scaldante e Totalizzatore dei Tempi di Inserzione; Ente Nazionale Italiano di Unificazione: Milano, Italy, 2010

11. UNI 10200, Impianti termici centralizzati di climatizzazione invernale e produzione di acqua calda sanitaria - Criteri di ripartizione delle spese di climatizzazione invernale ed acqua calda sanitaria, Ente Nazionale Italiano di unificazione, Milano, 2013

12. L. Celenza, M. Dell'Isola, G. Ficco, B.I. Palella, G. Riccio, Energy and Buildings, 95, 47-56 (2015)

13. G. Ficco, L. Celenza, M. Dell'Isola, P. Vigo, Energy and Buildings, 130, 477-487 (2016)

14. F. Arpino, G. Cortellessa, M. Dell'Isola, G. Ficco, R. Marchesi, C. Tarini, Energy Procedia, 101, 74-80 (2016)

15. F. Saba, V. Fernicola, M.C. Masoero, S. Abramo, Buildings, 7, 20 (2017)

16. F. Bari, D. Mereu, C. Damarco, C. Greco, S. Malan, G. Marchetto, S.R. Tirado, R. Tisseur, M. Violante, G. Zangari, et al., Energy Procedia, 78, 2977-2982 (2015)

17. C. Marinari, F. Saba, M. Orio, Preliminar Verification of the Functionality and the Accuracy of Heat Metering and Cost Allocation Devices at the INRIM Central Heating System Simulator: The EcoThermo Soft-Sensor Procedure (Technical Report n9/2015, INRIM, Torino, Italy, 2015)

18. C. Marinari, F. Saba, F. Grisotto, M. Orio, M. Masoero, Energy Procedia, 78, 23042309 (2015)

19. IAPWS 2007 Revised Release on the IAPWS Industrial Formulation 1997 for the Thermodynamic Properties of Water and Steam; International Association for the Properties of Water and Steam, Lucerne, Switzerland, 2007

20. IAPWS Advisory Note No. 1 Uncertainties in Enthalpy for the IAPWS Formulation 1995 for the Thermodynamic Properties of Ordinary Water Substance for General and Scientific Use (IAPWS-95) and the IAPWS Industrial Formulation 1997 for the Thermodynamic Properties of Water and Steam (IAPWS-IF97); International Association for the Properties of Water and Steam, Vejle, Denmark, 2003 